\title{
Doctors trial amiodarone for Ebola in Sierra Leone
}

\author{
Fabio Turone
}

Milan

Ebola patients in Sierra Leone will receive amiodarone, a well known and cheap anti-arrhythmia drug, in a randomised controlled trial led by the Italian non-governmental organisation Emergency.

The trial is expected to start in a few weeks, when a 100 bed hospital recently built by the UK Department for International Development will be entrusted to Emergency. The hospital is one of six built as part of Britain's $£ 250 \mathrm{~m}$ ( $€ 314 \mathrm{~m}$; $\$ 395 \mathrm{~m}$ ) effort to fight the Ebola virus in Sierra Leone.

Roberto Satolli, the trial's coordinator, told The BMJ,

"Amiodarone, a multi-ion channel inhibitor and adrenoceptor antagonist, showed in preclinical studies to be a potent inhibitor of filovirus cell entry. Since it has been used for many decades on millions of patients, its safety profile is well known, and it appears to be a good candidate for a phase III trial.

"After the World Health Organization set the new ethical framework for research on Ebola, we administered the drug as a compassionate therapy to all 65 patients hospitalised in our 22 bed treatment centre in Lakka, where we recorded an overall mortality of $63 \%$, without being able to determine whether the drug had any effect."

Emergency, which provides medical relief in 16 countries, has treated more than 464000 patients in Sierra Leone since 2001 in a surgical centre and a paediatric centre, both located in Goderich, Freetown. The centres provide free medical care and have remained open during the present Ebola outbreak.

Gino Strada, the surgeon who founded Emergency in 1994, told The BMJ, "To prevent the spread of Ebola in those centres, in mid-September we opened a holding centre in Lakka to triage suspected Ebola cases, and very soon we started treating them."

After the new hospital opens in Goderich on 14 December the facility in Lakka will revert to being a holding centre, where a new laboratory will allow fast polymerase chain reaction testing. A minimum of 132 patients with confirmed Ebola virus infection will then be randomised to receive amiodarone and best supportive care or best supportive care alone, in a ratio of 2:1. A Ugandan paediatrician working with Emergency who contracted the virus in Sierra Leone was declared cured on 21 November after being hospitalised in Frankfurt, Germany. And on 24 November another doctor working for Emergency in Sierra Leone-an Italian doctor whose identity was not disclosed-was found to have the Ebola virus and was immediately flown to the Spallanzani Hospital in Rome for treatment.

Cite this as: BMJ 2014;349:97198

๑ BMJ Publishing Group Ltd 2014 